\title{
Balkanologie
}

Balkanologie Revue d'études pluridisciplinaires

Vol. IV, $n^{\circ} 1 \mid 2000$

Volume IV Numéro 1

\section{Kičevski (Nikola), Trsje i Trsjani (Le village de Trsje et ses habitants),}

Skopje : Association des enfants réfugiés de la partie égéenne de la Macédoine, 1998, $307 \mathrm{p}$.

Bernard Lory

\section{(2) OpenEdition}

Journals

Édition électronique

URL : http://journals.openedition.org/balkanologie/2204

DOI : 10.4000/balkanologie.2204

ISSN : 1965-0582

Éditeur

Association française d'études sur les Balkans (Afebalk)

Édition imprimée

Date de publication : 1 septembre 2000

ISSN : 1279-7952

Référence électronique

Bernard Lory, « Kičevski (Nikola), Trsje i Trsjani (Le village de Trsje et ses habitants), », Balkanologie [En ligne], Vol. IV, $n^{\circ} 1$ | 2000, mis en ligne le 29 juillet 2010, consulté le 17 décembre 2020. URL : http:// journals.openedition.org/balkanologie/2204; DOI : https://doi.org/10.4000/balkanologie.2204

Ce document a été généré automatiquement le 17 décembre 2020.

(c) Tous droits réservés 


\section{Kičevski (Nikola), Trsje i Trsjani (Le village de Trsje et ses habitants),}

Skopje : Association des enfants réfugiés de la partie égéenne de la Macédoine, 1998, 307 p.

Bernard Lory

\section{RÉFÉRENCE}

Kičevski (Nikola), Trsje i Trsjani (Le village de Trsje et ses habitants), Skopje : Association des enfants réfugiés de la partie égéenne de la Macédoine, 1998, 307 p.

1 Quittons les hautes sphères de la diplomatie internationale, laissons les enjeux nationaux et régionaux, descendons sur le terrain, au niveau le plus humble, celui d'un pauvre village de montagne, dans un coin perdu des Balkans. Touchons-en les cailloux, les forêts, les prairies, les routes bloquées par la neige en hiver. Jetons un regard sur ses habitants, sur leurs travaux et leurs jours... Et voici qu'à ce niveau le plus humble, au fin fond de la cambrousse balkanique, l'Histoire vient nous rattraper: querelles de clochers, bandes armées, armées régulières, traités, États, frontières, Grandes puissances, monde bi-polaire. Comme aspirés par une tornade, nous voilà projetés dans la stratosphère!

2 Cette plongée-remontée, ce jeu de ludion entre le local et le global, est un exercice salutaire pour le balkanologue. C'est aussi une source d'émotions fortes, de vertiges subtils, de stupeur et de chagrin. Il permet d'approcher au plus près du vécu la tragédie balkanique.

La procédure est des plus simples : il suffit de délaisser les historiens académiques, pour puiser dans le trésor méconnu des monographies locales. Il faut rendre hommage à cette micro-histoire, limitée à un village ou à un canton, en soulignant son approche pluridisciplinaire, qui allie géographie, ethnographie, économie, dialectologie, etc. Ses auteurs, souvent d'anciens instituteurs, n'ont pas de hautes prétentions scientifiques, mais ils connaissent bien leur terrain. Ils mettent en forme pour nous toute une 
mémoire collective, qui s'articule autour de toponymes, d'anecdotes ou de souvenirs familiaux. Leur exposé est parfois maladroit ou empreint de parti pris, mais cela ne constitue pas un obstacle, car ils sont faciles à dépister. Leur émotionnalité-même est un gage d'authenticité.

Parmi des dizaines d'ouvrages aux mérites comparables, nous nous arrêterons sur celui de Nikola Kičevski, pour le caractère émouvant de son entreprise. Le village qu'il nous présente, Trsje (Trivounon depuis 1927), à une quinzaine de kilomètres au sud-ouest de Florina, est en effet aujourd'hui abandonné.

C'était un village slavo-macédonien que la pauvreté de son terroir montagneux condamnait au gurbet, à la migration économique. De son passé séculaire l'on a que fort peu de traces. Et puis un jour la parole écrite, les passions nationales et la violence font toutes ensemble irruption dans sa vie. En moins d'un siècle, l'Histoire va saigner, broyer et disperser le village de Trsje.

Celui par qui le malheur arrive est présenté comme une figure de héros ou de saint. C'est le père Gerasim (1820-1891), qui ouvre la première école dans le village et lie son destin à la cause exarchiste. En contrepoint une autre figure d'ecclésiastique, funeste, celle-ci, se profile : celle de l'évêque Karavangelis de Kastoria, mélange de théologien et d'aventurier, chez qui la passion nationale prend le pas sur les sentiments chrétiens.

Nous assistons au jeu de cache-cache entre les bandes armées et les gendarmes : ce sont toujours les villageois les perdants! L'insurrection d'Ilinden en 1903 coïncide avec le début des migrations transatlantiques; ce nouveau gurbet permet au village de subsister, mais il dévore lentement sa jeunesse. Viennent les guerres et la délimitation des frontières. La région de Florina se trouve coupée de celles de Bitola et de Korça, n'ayant plus que Salonique comme unique débouché économique. L'État grec est perçu comme une marâtre par les "paléo-bulgares", toujours suspects aux yeux du pouvoir, même si le village contribue en victimes aux guerres d'Asie mineure, puis d'Albanie. L'amertume de l'auteur perce à chaque page.

Mais le pire reste encore à venir : la terrible décennie 1940-1950.

Aujourd'hui encore, il est difficile de déterminer quel fléau fut plus dévastateur et douloureux : la misère inouïe, les tortures et les souffrances infligées par les différentes armées, les traitres en armes de toutes couleurs, le désarroi et la désorientation des villageois, la colère de Dieu ou toute autre chose encore... (p. 204).

9 Trsje se retrouve en effet à la limite des zones d'occupation allemande et italienne. Les premiers maquisards à s'y présenter viennent de la région de Bitola. En 1943, le village passe sous le contrôle de l'EAM, mais la reconnaissance du fait macédo-slave ne vient que progressivement, durant l'été de 1944. Le récit que nous propose N. Kičevski, quoique lacunaire et empreint d'une phraséologie militante, n'en est pas moins éclairant. Il souligne la misère des villageois, la nécessité du marché noir, les poulets rapinés par les soldats italiens; il désigne les collaborateurs locaux, qui jouent la carte bulgare ou grecque-monarchiste en cassant les solidarités communautaires.

10 Trsje s'engage massivement du côté de l'Armée Démocratique Grecque durant la guerre civile. Le village est totalement brûlé par les forces gouvernementales en juin-juillet 1947. Ses habitants sont dispersés et 115 enfants sont "mis à l'abri" en Yougoslavie ou dans d'autres démocraties populaires. On connaît la tragédie de ces enfants, dont certains ne retrouveront leurs proches que vingt ans plus tard. L'écrasement de l'Armée Démocratique Grecque entraîne dans l'exil de nombreux Trsjani, en Macédoine 
yougoslave ou en Ouzbekistan. Pour ceux qui restent en deçà du rideau de fer, l'émigration vers le Canada et l'Australie (où ils retrouvent des villageois partis dans les années 1930) constitue une échappatoire économique à la crise qui touche toutes les zones montagneuses de Grèce du nord. La politique fait le reste : les derniers habitants $\mathrm{du}$ village seront relogés de force dans les faubourgs de Florina. Au recensement de 1991, Trsje / Trivounon ne comptait plus que deux habitants, depuis lors décédés.

11 Mais le village ne se réduit pas à des maisons et un territoire. La communauté des Trsjani, éparpillée sur plusieurs continents, n'a pas disparu. Le livre de N. Kičevski marque la volonté passionnée de maintenir le lien de mémoire qui les unit. Il fournit de longues listes de noms, d'anciens combattants, de victimes, de déportés, d'émigrés outre-mer, qui sont indifférents au lecteur étranger, mais qui pour l'initié désignent un grand-père, une tante, un cousin... Le livre enfin propose un matériau iconographique émouvant: photos de famille montrant les costumes d'autrefois, jeunes gens sous des uniformes divers, scènes d'orphelinat, vues contemporaines d'un village qui tombe en ruines.

\section{AUTEURS}

BERNARD LORY 